\title{
As masculinidades nas telenovelas do horário nobre da Rede Globo: uma proposta de observação da representação de um novo espectro de masculinidades à luz da Teoria Queer \\ Masculinities in Rede Globo's prime time telenovelas: an approach to a new spectrum of masculinities in light of Queer Theory
}

\author{
Daniela Jakubaszko \\ Professora da Escola de Comunicação da USCS - Universidade Municipal de São Caetano do Sul, Brasil. Doutora em Ciências \\ da Comunicação pela ECA-USP, Brasil. E-mail: ocadani@yahoo.com \\ João Nemi Neto \\ Professor da Columbia University of New York, Estados Unidos. Doutor em Hispanic and Luso-Brazilian Literatures and \\ Languages com uma concentração em LGBTQ Studies pelo Graduate Center/City University of New York, Estados Unidos. E- \\ mail: jn2395@columbia.edu
}

\section{Resumo:}

O presente estudo apresenta um levantamento, ainda em andamento, de personagens das telenovelas do horário nobre da Rede Globo que trabalhem com a representação de diferentes vivências de masculinidade. A proposta é dialogar com as questões de gênero, a partir da teoria queer, de forma a perceber como a telenovela propõe a desconstrução do machismo e apresenta um espectro mais amplo de masculinidade, que inclua a diversidade de experiências e vivências mais próximas do cotidiano dos indivíduos (ou cidadãos) homens brasileiros. Como a telenovela constrói as representações das masculinidades? Há a prevalência de um ideal hegemônico ou ela trabalha a favor da diversidade? Como a desconstrução do machismo se faz presente na telenovela? Neste artigo, mostramos que muitos personagens que se identificam com o gênero masculino não se identificam com o modelo hegemônico, outros procuram se perceber fora da lógica masculino-feminino e, por fim, alguns chegam a ultrapassar a lógica binária, assumindo uma identidade de gênero feminina.

\section{Palavras-chave:}

Comunicação; Teoria Queer; Masculinidades; Telenovela brasileira.

\begin{abstract}
:
In which ways does the Brazilian telenovela construct representations of masculinity? Is there a prevalence of a hegemonic ideal or does it work in favor of diversity? In which ways does the deconstruction of machismo make itself present in the telenovela? This paper presents an ongoing mapping of telenovela characters from Rede Globo's prime time that deal with different experiences and representations of masculinity. The goal is to discuss questions of gender, using queer theory as a theoretical framework, trying to understand how the telenovela proposes the deconstruction of chauvinism
\end{abstract}


and presents a broader spectrum of masculinity that includes a diversity of experiences of Brazilian individuals. We present a number of characters that identify themselves as males however do not identify themselves with the hegemonic model. Other characters see themselves outside the masculine-feminine logic, and others go beyond the binary logic, taking on a female gender identity.

\section{Keywords:}

Communication; Queer Theory; Masculinities; Brazilian Telenovela.

\section{Introdução}

A masculinidade acha-se presente nas vivências de cada homem, sem distinção, e até mesmo antes de outros fatores como lugar de origem, religião, profissão, pertença a grupos distintos etc. As crianças, desde os seus primeiros dias de vida, são orientadas e direcionadas para a escolha e o gosto de tudo aquilo que é típico de seu sexo de nascimento. Os ambientes, as roupas, objetos, brinquedos e brincadeiras, o linguajar, o comportamento, enfim, as nossas práticas e experiências estão impregnadas dos signos e símbolos que caracterizam o masculino e o feminino. Não há dúvidas de que muito da cultura se organiza conforme a divisão de tarefas entre os sexos, ainda que os papéis variem de cultura para cultura, de época para época. $\mathrm{O}$ resultado é um conjunto de práticas, símbolos, representações, normas, regras e valores sociais elaborados em decorrência da diferença de sexo. Nessa trama social adquirem sentido, por exemplo, as práticas reprodutivas da espécie humana, a satisfação dos impulsos sexuais, as relações entre os homens, entre as mulheres, e entre ambos, os espaços próprios de cada um, os atributos adequados às posições (e aos lugares) sociais que ocupam, as normas e códigos de conduta, o estabelecimento de hierarquias, privilégios e sanções, e até mesmo a distribuição de recursos nas esferas de poder. Assim se estabelecem também as relações de dominação e subordinação, a desigualdade entre os gêneros, a organização do trabalho, a definição de uma agenda pública. Bourdieu observa que:

A divisão entre os sexos parece estar na ordem das coisas[...] ela está presente, ao mesmo tempo, em estado objetivado [...] em todo o mundo social, e em estado incorporado, nos corpos e nos habitus dos agentes, funcionando como sistemas de esquemas de percepção, de pensamento e de ação. (BOURDIEU, 2007, p. 17).

INTERIN, v. 23, n. 2, jul./dez. 2018. ISSN: 1980-5276. 
A masculinidade se exerce através de pensamentos, comportamentos e sentimentos. Há diversas práticas - variáveis de cultura para cultura, épocas, classe social, faixa etária, valores referenciais, entre outros - que se inscrevem no âmbito do exercício da masculinidade. O machismo, por exemplo, aparece como um valor negativo, como a exacerbação de alguns traços da masculinidade que objetiva o domínio do homem sobre a mulher, de alguns homens sobre outros homens. É um conjunto de crenças, sentimentos e condutas que ao definir "o que é ser homem" impõe superioridade e exerce domínio e implica que há um "outro" que "não é homem". A violência aparece como uma forma de manter e assegurar a suposta superioridade e domínio.

Fatores como o feminismo, a Aids, o movimento gay, as novas formas de sociabilidade, as subjetividades trans, entre outros, questionam, há décadas, a legitimidade da dominação masculina, a naturalidade com que ela tem sido concebida e praticada. Não obstante, pode-se dizer que o homem ainda se beneficia de privilégios na sociedade contemporânea. Para Bourdieu há, no senso comum, um discurso que legitima a prática da supremacia masculina. Por outro lado, "a maior mudança está, sem dúvida, no fato de que a dominação masculina não se impõe mais com a evidência de algo que é indiscutível" (BOURDIEU, 2007, p. 106).

Após pesquisas e ativismo político ao longo do século $\mathrm{XX}$, a ideia de masculinidade - no singular - vem sendo questionada e reconfigurada. No Brasil, Goldenberg (2003) realizou uma pesquisa com cerca de 1300 homens e mulheres entre 20 e 50 anos, investigando a representação do gênero na mídia. A maioria dos entrevistados se percebe à margem de um ideal de masculinidade apregoado pelas mídias. As pessoas, nos dias de hoje, relacionam-se de maneiras que vão além das tradicionais posições binárias. Identidades de gênero e de orientação sexual são reconfiguradas de maneira que passem a representar formas mais abrangentes de expressão sexual e identitária. Aos poucos, as representações televisivas estão se aproximando desta realidade, demonstrando uma abertura para as narrativas de diferentes e variadas possibilidades de exercício da masculinidade.

Partimos do princípio, portanto, de que está em curso uma proposta de ruptura com o modelo hegemônico de masculinidade, e de abertura para variadas expressões da masculinidade. Trabalhamos com a hipótese de que a telenovela reflete e refrata

INTERIN, v. 23, n. 2, jul./dez. 2018. ISSN: 1980-5276. 
este momento de transição, registrando e reformulando o seu espaço-tempo e as suas narrativas. Neste artigo, por meio de um levantamento e estudo de personagens das telenovelas do horário nobre da Rede Globo, na primeira década do século XXI, buscamos observar como o gênero vem construindo e ampliando espaço para tais representações. Acredita-se que, por meio de suas narrativas, conflitos e personagens, por meio ampliação do espectro de masculinidades representadas, a ficção televisiva contribui para a desconstrução do machismo.

\section{Caracterização do estudo}

Desde os anos 70 as telenovelas vêm mostrando e registrando o processo de emancipação da mulher brasileira: do direito ao desquite, ao divórcio, a não esperar virgem pelo casamento - ou pelo menos a não estigmatizar aquela que não quer esperar -, a ser mãe solteira, a arriscar uma carreira de sucesso, a fazer inseminação artificial, a ter uma "produção independente", a ver o marido agressor ser julgado pela Lei Maria da Penha. Não que o entretenimento precise ter algum compromisso com os ideais feministas, mas é evidente que seus produtos precisam estar de acordo com as experiências cotidianas de suas espectadoras se quiser dialogar com elas. As mulheres, no Brasil, estudam mais que os homens - embora ainda recebam menos pelas mesmas funções - e cresce a cada ano o número de mulheres que chefiam famílias. Apenas este fato já mostra o quão intensa é a agenda feminina. E a realidade é muito mais ampla do que se mostra nas estatísticas, na ficção televisiva, ou na propaganda, ou na mídia, por meio dos estereótipos.

Processos revolucionários já estão ocorrendo na infraestrutura da vida pessoal. A transformação da intimidade reclama por mudança psíquica e também por mudança social, e essa mudança, partindo "de dentro pra fora", poderia potencialmente se ramificar através de outras instituições, mais públicas. (...) A promoção da democracia no domínio público foi, de início, primordialmente um projeto masculino - do qual as mulheres afinal conseguiram participar, sobretudo através da sua própria luta. A democratização da vida pessoal é um processo menos visível, em parte justamente por não ocorrer na área pública, mas suas implicações são também muito profundas. É um processo em que, de longe, as mulheres desempenharam papel principal, ainda que no fim, os benefícios alcançados, assim como na esfera pública estejam abertos a todos. (GIDDENS, 1993, p. 200-201). 
A telenovela participou deste processo, ainda que com representações muitas vezes machistas ou contraditórias. À medida que acontece o fortalecimento da luta feminista e LGBT na esfera pública, a representação de personagens homossexuais, sutil e não declarada até a década de 80 , começou a se evidenciar na década de 90 e a se fazer presente, de maneira cada vez mais significativa, ainda que não sem polêmicas, na primeira e segunda décadas deste século. Assim, é durante a primeira e segunda décadas do século XXI que começa a tornar-se recorrente a presença de personagens gays e lésbicas, não apenas no horário nobre, e com diversidade nas representações (LOPES; GÓMEZ, 2012; 2015). Também aparecem formações poliamorosas, além dos triângulos amorosos. Em A Favorita, por exemplo, foi identificada a presença de 11 triângulos amorosos se formando e desfazendo durante a novela (JAKUBASZKO, 2010).

Assim, nossa proposta é dialogar com as questões de gênero, a partir de elementos da teoria queer, de forma a perceber como a telenovela propõe a desconstrução do machismo por meio das representações de masculinidade de espectro mais amplo, que inclua a diversidade de experiências e vivências mais próximas do cotidiano do homem brasileiro da atualidade. Desde pesquisas anteriores vem se confirmando a hipótese de que diversas personagens são construídas com a proposta de trazer questões de gênero para o debate público (JAKUBASZKO, 2010). Dentre as que se apresentam com este propósito, e que se identificam com o gênero masculino, todas elas contribuem para combater as práticas de machismo, opressão e dominação masculina; algumas podem se perceber fora da lógica binária masculino-feminino, questionando-a; e, por fim, algumas personagens que podem ultrapassar esta lógica, assumindo uma identidade de gênero feminina ou trans.

\section{Reflexões teóricas}

\subsection{Masculinidades e suas representações}

Ainda que nos dias de hoje seja comum pensar em masculinidade dentro de uma visão binária e machista, propomos neste trabalho redefinir o conceito ampliandoo para diversas manifestações do masculino, incluindo também possibilidades do

INTERIN, v. 23, n. 2, jul./dez. 2018. ISSN: 1980-5276. 
feminino. Afinal, a ideia que se faz comumente sobre o que é masculinidade costuma estar relacionada a uma visão estereotipada do que viria a ser homem. Se tal visão é uma construção, propomos aqui desconstruí-la e abrir caminho para novas vivências de masculinidade, para que pessoas possam ter o direito de viver suas identidades sexuais e de gênero fora de padrões herdados, se quiserem, ou pelo menos aceitar que diferentes representações circulem livremente.

A partir da ideia de que o homem é o sujeito e a mulher, o objeto, ao longo dos anos criou-se a noção de binarismo nas dimensões de identidade de gênero e orientação sexual. Ou seja, desde a ideia de invertido sexual até a noção de travestismo passa-se pelo crivo do masculino como ponto inicial para a compreensão da identidade de gênero.

No final dos anos 60 e começo dos anos 70 os estudos literários gays começaram a florescer no mundo acadêmico norte-americano. À medida que o movimento homossexual começou a buscar e a criar uma cultura e identidade próprias, passou a olhar não só para o passado, mas também para o futuro. $\mathrm{Na}$ década de 80 , o ativismo político norte-americano, ainda mantendo esse olhar no passado, adotou a palavra queer como força motora do movimento, sendo que, até então, este vocábulo era considerado o termo homofóbico mais usado no país. Ou seja, o movimento político resgata e incorpora um vocábulo, antes de conotação negativa, tentando, assim, desconstruir o significado demeritório, pejorativo.

Nas universidades, a teoria queer procura denunciar a heteronormatividade que atinge inclusive o movimento gay. Em "Queer Theory. Lesbian and Gay Studies Sexualities: an Introduction", Teresa de Lauretis (1991) afirma que o termo queer deveria funcionar como algo que incomode, justaposto a lésbico e gay do subtítulo, de modo a marcar certa distância crítica dos vocábulos usados anteriormente. Para De Lauretis, queer é o "não-canônico", polifônico, transgressor e problemático. Rafael Mérida (2002) nos ajuda a entender as práticas políticas da teoria queer dizendo que ser queer não significa lutar por um direito à intimidade, mas sim pela liberdade pública de ser quem somos, contra a opressão. Lugarinho (2002, p. 196), no mundo lusófono, diz que "o luso-queer precisa desconstruir a cultura em que ele ou ela está localizada e também problematizar a posição geopolítica da cultura em que sua identidade marginalizada emerge".

INTERIN, v. 23, n. 2, jul./dez. 2018. ISSN: 1980-5276. 
A teoria queer, que ao longo das últimas décadas do século $\mathrm{XX}$ foi se desenvolvendo e foi buscando compreender as questões de gênero e de identidade sexual, abriu caminho para que pudéssemos entender as identidades além do binarismo masculino-feminino. A ideia de masculinidade costuma estar diretamente associada à ideia de virilidade, comando e força. Ser masculino é a negação do feminino e principalmente do homossexual. Além das pesquisas teóricas que vimos acima, há várias pessoas que estão procurando questionar tais conceitos em suas vidas. Chad States, por exemplo, um artista norte-americano, se propôs a fotografar pessoas independentemente de suas identidades, a partir de suas próprias ideias de masculinidade. Ele colocou um anúncio online e fotografou as pessoas em seus espaços de circulação. $\mathrm{O}$ anúncio não especificava gênero e como respostas obteve chamados de homens, mulheres, e pessoas não-binárias ${ }^{1}$.

Em seu famoso texto "Is the Rectum a Grave", Leo Bersani (2010) retoma a discussão fazendo uma crítica à apropriação do "estilo macho" descrito por Jeffrey Weeks. Para Bersani, ainda que exista a apropriação da cultura do macho dentro da comunidade homossexual dos anos 70, o "crepúsculo do macho", como Fernando Gabeira chamou o fenômeno nos anos 80, não é ameaçado. Além da sexualização da estética "masculina", há a apropriação do heterossexismo e reprodução de formas de opressão contra os "dissidentes".

Tal ideia ainda persiste nos dias de hoje. Em uma entrevista ao jornal Folha de São Paulo $(09.03 .2014)^{2}$, Luis Mott critica as telenovelas brasileiras por apenas mostrar personagens caricatos, pois, de acordo com o pesquisador, "[n]a vida real, os gays são másculos na maioria". Em primeiro lugar, a afirmação de que os gays másculos são maioria parte de um juízo em que seria preciso saber qual é a masculinização proposta. Também, em um segundo momento, é preciso levar em conta quem são esses personagens presentes na telenovela. Finalmente, e talvez o mais importante para nós, é refletir sobre o que está por trás desse "desejo" de

\footnotetext{
${ }^{1}$ De acordo com o site: "I found all my subjects through Craigslist. I began by asking the question "Are you masculine?" in the heading. In the body of the posting I talked briefly about the project. Much to the effect of: "I am doing a photography project on masculinity. If you identify as being masculine, please get back to me." I intentionally leave it gender-neutral so males, females and transpeople feel free to respond. Most of the respondents are men, but a few are female and a few are trans". Disponivel em: <https://goo.gl/im4drC $>$. Acesso em: 01/11/2016.

${ }^{2}$ Disponível em: $<\mathrm{https} / /$ goo.gl/xYz1kh $>$. Acesso em: 01/11/2016.
}

INTERIN, v. 23, n. 2, jul./dez. 2018. ISSN: 1980-5276. 
masculinidade que acabou por excluir muitos corpos não-normativos ao longo das últimas décadas. Para David Halperin (2012), tal reclamação mostra, além do escrutínio que identidades não-normativas recebem na sociedade, a confusão entre identidade de gênero e orientação sexual.

Através de textos como os analisados por Halperin e até na entrevista de Luiz Mott, pode-se perceber, ainda nos dias de hoje, que muitas das pessoas que resistem aos valores tradicionais da masculinidade acabam marginalizadas. Porém, aos poucos, podemos observar indivíduos que desafiam os padrões normativos apresentando novas possibilidades de representações identitárias, tanto de gênero quanto sexuais.

\subsection{Identidade de gênero e orientação sexual}

Conforme dissemos anteriormente, as pesquisas e vivências individuais ao longo do século XX reformularam de maneira radical a maneira como pensamos a nossa sexualidade. Desde o seminal texto de Simone de Beauvoir, em que a filósofa afirma que não se nasce uma mulher, mas sim, torna-se, muito tem se discutido e proposto a respeito do assunto. Atualmente, chamam nossa atenção, por exemplo, as recentes e frequentes declarações de Laerte sobre sua transição de identidade de gênero, o prazer que sente com o processo, como também as reações - negativas e positivas - que provoca em seu entorno. Um dos diálogos intrigantes e que mostra como a questão de gênero está entrelaçada com aspectos políticos e sociais, aconteceu com algumas amigas travestis, que afirmaram à cartunista que ela é "transsexual" e não "travesti", fazendo-a notar como, no Brasil, a referida denominação está carregada de preconceito de classe, marcando uma fronteira social e não propriamente de gênero. Noção reproduzida inclusive pelas próprias travestis (Roda Viva, TV Cultura, $20 / 02 / 2012)^{3}$.

Um dos pontos centrais na discussão sobre sexualidade é a ideia de identidade ou de identidades. Quando a categoria homossexual passa a ser usada no final do século XIX, cria-se um termo médico-legal que categoriza o outro a partir de dados científicos. Ao longo do século XX, passamos a pensar em identidade como

\footnotetext{
${ }^{3}$ Disponível em: <https://goo.gl/MSB6j7>. Acesso em: 05/11/2016.

INTERIN, v. 23, n. 2, jul./dez. 2018. ISSN: 1980-5276.
} 
autodefinida, ou seja, o indivíduo tem a liberdade de se identificar da maneira que lhe pareça mais apropriada. E a partir dessa experiência, novas identidades e categorias começam a ser redefinidas, reinventadas.

Quando o movimento de liberação homossexual eclode nos anos 70 nos Estados Unidos, no Brasil privilegia-se a política identitária fixa: homossexuais, heterossexuais e bissexuais. A população "trans" é mantida invisível em uma plataforma heteronormativa de assimilação ao status quo. Ao longo das décadas, tais identidades passaram a ser mais visíveis e suas demandas políticas precisavam ser ouvidas. Hoje em dia, podemos mencionar Laverne Cox, uma atriz americana de grande sucesso nos Estados Unidos. No Brasil, Lea T é uma modelo internacional que se identifica como transsexual. O grupo musical "As Bahias e a cozinha mineira" é liderado por duas mulheres trans. Em 2016, a L'Oreal fez uma campanha com a modelo trans Valentina Sampaio no Dia das Mulheres e, em outubro de 2016, aparece em sua primeira capa da revista, a Elle brasileira ${ }^{4}$.

É importante ressaltar que as questões de identidade de gênero e orientação sexual vão se expandindo à medida que vamos encontrando novas formas identitárias. O Manual de Comunicação LGBT produzido em 2009 pela ABGLT, por exemplo, tem o intuito de "reduzir o uso inadequado e preconceituoso de terminologias que afetam a cidadania e a dignidade de 20 milhões LGBT no país, seus familiares, amigos, vizinhos e colegas de trabalho" (ABGLT, 2009, p. 5). O Manual apresenta uma lista de palavras com as suas definições para que cidadãos e profissionais da área de comunicação e pesquisa possam se comunicar de maneira que não se ataque a população LGBT de maneira negativa.

De maneira sucinta, o manual apresenta primeiramente a diferença entre identidade de gênero e orientação sexual, distinção fundamental para os trabalhos de gênero e sexualidade. Orientação sexual refere-se à capacidade que uma pessoa tem por se interessar afetivamente, emocionalmente e sexualmente por um outro indivíduo. Até meados da primeira década do século XXI, falava-se em homossexualidade, heterossexualidade e bissexualidade. Identidade de gênero, por sua vez, refere-se à

${ }^{4}$ Disponível em: <https://goo.gl/AZSWsG>. Acesso em: 08/11/16.

INTERIN, v. 23, n. 2, jul./dez. 2018. ISSN: 1980-5276. 
“experiência interna e individual do gênero de cada pessoa que pode ou não corresponder ao sexo atribuído no nascimento" (ABGLT, 2009, p. 17).

À medida que a teoria queer avança na academia norte-americana o ativismo vai tomando rumos mais inclusivos e entre outras medidas adota, nos Estados Unidos, o Q em sua sigla, LGBTQ (Lesbians, Gays, Bissexuals, Transexual and Queer). Queer inicialmente valia para as pessoas que não se identificavam com nenhum dos termos propostos pela militância norte-americana.

O termo queer, que muitas vezes é visto como um "guarda-chuva" que compreende várias identidades de gênero e orientações sexuais, começa a dar espaço para novas identidades e também antigas expressões que ganham espaço e visibilidade. Para o nosso trabalho, propomos pensar nas questões de sexualidade e gênero a partir das identidades a seguir.

No que diz respeito à identidade de gênero, elencamos os seguintes termos:

- Gênero-fluído: pessoas que transitam entre diferentes gêneros como homem, mulher, agênero;

- Não binário: não se identificam com o gênero dado ao nascer ou identidades propostas socialmente;

- Demigênero: se identificam parcialmente com um gênero;

- Agênero: não se identificam com nenhum gênero proposto;

- Travestis: se identificam com o gênero feminino na maioria dos casos, passam por transformações corporais para se aproximarem do gênero feminino, mas optam por não fazer a cirurgia de readequação sexual;

- Transsexuais FTM: pessoas designadas mulheres ao nascer, mas não se identificam como tal e passam por processos de readequação de gênero e sexo;

- Transexuais MTF: pessoas que foram designados homens ao nascer, mas não se identificam como tal e passam por processos de readequação de gênero e sexo;

- Transgêneros: pessoas que transitam entre os gêneros;

- Cisgênero: quem se identifica com o gênero que lhe foi atribuído ao nascer;

- Crossdresser: pessoas cisgênero, em sua maioria, que se identificam com o outro gênero através de sua vestimenta e atitudes, mas não necessariamente procuram readequação química ou cirúrgica.

INTERIN, v. 23, n. 2, jul./dez. 2018. ISSN: 1980-5276. 
É importante ressaltar que ainda que a lista pareça fixa, ela não é exaustiva e não está livre de polêmicas ou questionamentos. Por exemplo, fala-se muito hoje se a cirurgia de adequação de sexo é realmente necessária para que uma pessoa possa legalizar a transição de gênero. Léo Áquila, uma transexual brasileira, tem falado sobre sua condição em que um impedimento físico lhe proíbe de fazer a cirurgia, mas que ainda assim, é uma mulher. A Argentina é o primeiro país da América Latina a aceitar que pessoas trans possam mudar a identidade de gênero dos documentos oficiais sem que a cirurgia seja obrigatória.

Em relação à orientação sexual, podemos elencar as seguintes condições:

- Bissexual: São pessoas que se sentem atraídas física e emocionalmente por pessoas dos dois gêneros - masculino e feminino;

- Homossexual: São pessoas que se sentem atraídas física e emocionalmente por pessoas do mesmo gênero que o dela;

- Heterossexual: São pessoas que se sentem atraídas física e emocionalmente por pessoas de gênero diferente do dela;

- Assexual: São pessoas que não experenciam desejo sexual;

- Pansexual: São pessoas cujo desejo sexual pode ir além do desejo por outros indivíduos (objetos, por exemplo).

Assim como na lista anterior, há pontos que se podem (e se devem) questionar. Vale notar que tais categorias provavelmente ainda não dão conta de abarcar toda a diversidade que podemos encontrar. E há muitas combinações possíveis entre as noções de identidade de gênero e de orientação sexual, que não são exclusivas nem excludentes. Uma pessoa cisgênero pode identificar-se como assexual, homossexual ou heterossexual, assim como uma pessoa crossdresser também pode identificar-se de maneiras diversas.

Há ainda, e de bastante relevância, o conceito "intersexual" que abrange uma "variedade de condições (genéticas e/ou somáticas) com que uma pessoa nasce, apresentando uma anatomia reprodutiva e sexual que não se ajusta às definições típicas do feminino ou do masculino" (ABGLT, 2009, p. 14). Vale lembrar que, ainda na década de 90, na Rede Globo, um personagem intersexual fez parte da novela Renascer de Benedito Ruy Barbosa (1993).

INTERIN, v. 23, n. 2, jul./dez. 2018. ISSN: 1980-5276. 


\section{Resultados preliminares: levantamento das personagens para análise}

A seguir, apresentamos resultados preliminares do levantamento das personagens das telenovelas do horário nobre da Rede Globo que, até o momento, integram a amostra, que não se pretende exaustiva, mas é capaz de revelar a diversidade presente nas representações das masculinidades e que serão analisadas em etapas futuras deste estudo.

Para compor o levantamento consultamos pesquisas anteriores sobre o mesmo tema (JAKUBASZKO, 2010; 2014); os Anuários do Obitel (LOPES; GÓMEZ, 2012) e Obitel Brasil (LOPES; GÓMEZ, 2015); sites da emissora; seções de jornais e blogs especializados em telenovela. A frequência e recorrência na mídia dos comentários feitos às personagens, assim como as fabulações cotidianas - TV, rádio, Facebook, Whatsapp, Twitter, conversação oral - em torno das narrativas e desempenho dos atores foram considerados na escolha da amostra já que a intensidade do debate indica a tematização da questão de gênero e identificação/rejeição das audiências (MOTTER; JAKUBASZKO, 2007).

Se o contexto contemporâneo evidencia a diversidade de gêneros e experiências de masculinidade, a telenovela, por mais que nele inserida, ao dialogar com o senso comum, se vê na constante tensão entre as audiências conservadoras e progressistas. A comunicação é um continuum e cada telenovela se torna um elo que permite o diálogo entre as anteriores e as posteriores. Nesse processo, a telenovela se constrói e se reinventa como gênero do discurso (BAKHTIN, 2003) num diálogo contínuo entre autores, novelas, audiência e entre eles com a sociedade do presente e do passado. Os estudos anteriores mostram que personagens narram a desconstrução do machismo e representam diferentes vivências da masculinidade. Ainda assim, o beijo gay demorou cerca de 10 anos para acontecer desde suas primeiras expectativas.

Na primeira década do século, no ano de 2003, Manoel Carlos, em Mulheres Apaixonadas, termina a longa e difícil trajetória de Rafaela (Paula Picarelli) e Clara (Aline Moraes) representando a união de duas garotas lésbicas com um "selinho" entre Romeu e Julieta, que as namoradas encenavam no teatro da escola. Tanto em América (2005, Glória Perez) quanto em Paraíso (2007, Gilberto Braga), o beijo gay foi esperado, mas não aconteceu. Duas Caras (2007-2008, Aguinaldo Silva) representa

INTERIN, v. 23, n. 2, jul./dez. 2018. ISSN: 1980-5276. 
uma formação poliamorosa entre dois homens e uma mulher, um deles homossexual, mas que nutria sentimentos e desejo pela mulher.

A partir de 2011, aumenta o número de personagens homossexuais em todos os horários (LOPES; GÓMEZ, 2012). Insensato Coração (Gilberto Braga e Ricardo Linhares) apresenta 6 personagens homossexuais e tematiza o tema da homofobia. $\mathrm{Na}$ época, estava em discussão no Congresso Nacional o Projeto de Lei 122/2006 que criminaliza, dentre outras agressões, aquelas motivadas por homofobia. O machismo é fortemente denunciado e criticado pela telenovela. Gilvan (Miguel Roncato) é assassinado por Vinícius (Thiago Martins) ${ }^{5}$, líder da gangue de homofóbicos que sai pelas ruas agredindo homossexuais._Vinícius acaba sendo preso no dia do próprio casamento. $\mathrm{O}$ vilão, para não deixar dúvidas sobre sua virilidade, forçou o intercurso sexual com a noiva ${ }^{6}$. As duas cenas são bastante fortes. $O$ assunto é importante e merece dramaticidade, as estatísticas da violência por homofobia no Brasil e dos casos de violência sexual doméstica impressionam.

Em Fina Estampa (2011, Aguinaldo Silva), no primeiro capítulo, os protagonistas se conhecem e se atraem ${ }^{7}$. De classes sociais distintas, o que os aproxima é o fato de Renê (Dalton Vigh) ser um homem bastante feminino e ela, Griselda, mais conhecida por Pereirão (Lilia Cabral), bastante masculina. O romance sobrevive até que ambos "equilibram" seus lados masculino e feminino da personalidade. O par amoroso central não reproduz o modelo padrão, também rompe com o final feliz do casal no final da novela; é a representação de que atualmente estão ficando borradas as fronteiras entre os atributos femininos e masculinos, e esse "intercâmbio de atributos" entre os gêneros origina "homens femininos" e "mulheres masculinas", mesmo que heterossexuais. Outras personagens evidenciam a mesma flexibilidade. Uma das funcionárias de Griselda na empresa "Maridas de Aluguel" é a trans FTM Fabrícia (Luciana Paes) que espera na lista do SUS o dia de sua cirurgia. Vale observar que personagens trans, travestis ou crossdresser, ultimamente, ao que

\footnotetext{
${ }^{5}$ A cena está disponível em: $<$ https://goo.gl/iMbXfJ $>$. Acesso em: 05/11/2016.

${ }^{6}$ A cena está disponível em: <https://goo.gl/3pQS5C>. Acesso em: 05/11/2016.

${ }^{7}$ A cena está disponível em: $<$ https://goo.gl/Pr9jQM $>$. Acesso em: 05/11/2016.
}

INTERIN, v. 23, n. 2, jul./dez. 2018. ISSN: 1980-5276. 
parece, estão mais presentes nas tramas do horário das $19 \mathrm{~h} 00^{8}$, a maioria em núcleos cômicos, alguns se propõem a tematizar a questão, outros não. Ainda em Fina Estampa, o gay efeminado interpretado por Marcelo Serrado fez tanto sucesso que logo depois da novela protagonizou o filme Crô.

Em Avenida Brasil (2012, João Emanuel Carneiro), o personagem de Alexandre Borges, Cadinho ${ }^{9}$, teve muito trabalho com suas mulheres: o empresário bem-sucedido do mercado financeiro mantém relacionamentos estáveis com três mulheres e seus filhos únicos com cada uma delas. Depois que as famílias se descobrem, resolvem constituir uma união estável, viver uma formação poliamorosa.

Em Amor à Vida, dia 31 de janeiro de 2014 foi ao ar no horário nobre o primeiro beijo entre dois homens na telenovela da Globo. Félix (Mateus Solano) foi um vilão gay efeminado que "roubou a cena" do par amoroso central e protagonizou, além do beijo gay, a última cena da novela. Para o gênero, trata-se de uma ruptura bastante significativa.

Na telenovela seguinte, de Manoel Carlos, Em Família, Giovanna Antonelli e Tayná Müller formaram um casal que provocou polêmica e alvoroço nas redes sociais. Em 2014-2015, na Império de Aguinaldo Silva, Xana (Ailton Graça) deixa dúvidas se é crossdresser ou transgênero até certo momento da trama. Tem um salão de beleza, mas já foi militar e enfermeiro. Muitas vezes parece ter um comportamento tipicamente masculino, apesar de predominar o universo feminino. Quer ter filhos e se casa para poder adotar uma criança. O namorado da moça mora um tempo com o “casal”, compondo mais uma formação poliamorosa.

Outro personagem, Cláudio Bolgari (José Mayer) é bissexual. Mantém relações homoafetivas fora do casamento. A mulher aceita e apoia sua orientação sexual, embora mantenham as aparências de casal heterossexual monogâmico. O conflito reside na revelação para o grupo, e na pressão que sofre de ambos os lados homossexual e heterossexual - para que se defina.

Quem tem dificuldades de aceitar é o filho do casal, não por acaso, personagem com feições de vilão. A ficção ainda está próxima da polêmica provocada pelo

\footnotetext{
${ }^{8}$ Conferir levantamento de Nilson Xavier. Disponível em: <https://goo.gl/6LuA93>. Acesso em: 05/11/2016.

${ }^{9}$ Disponível em: $<$ https://goo.gl/2j7bGo $>$. Acesso em: 05/11/2016.
}

INTERIN, v. 23, n. 2, jul./dez. 2018. ISSN: 1980-5276. 
deputado Marcos Feliciano, então presidente da Comissão de Direitos Humanos da Câmara dos Deputados, que propôs que psicólogos tratassem a homossexualidade como doença; a solução do roteirista para a narrativa é a aceitação de Cláudio como ele é, bissexual.

Em 2016, Breno (Otávio Müller) que se transformou em Valquíria A Regra do Jogo (João Emanuel Carneiro) é crossdresser de orientação heterossexual. A cena em que se revela crossdresser para a família chega a ser didática, servindo como uma conversa com cada um dos espectadores. A cena, ao mesmo tempo mostra, de acordo com a reação das diferentes personagens do núcleo, as seguintes respostas da sociedade para com aqueles que decidem assumir uma identidade de gênero diferente do sexo de nascimento; e, no caso, até com a orientação sexual: surpresa, riso, simpatia, encantamento, repulsa machista, choque. Reproduzimos alguns diálogos da cena ${ }^{10}$ :

\footnotetext{
Merlô - "só pra eu entender aqui, quer dizer que aos 45 do segundo tempo você resolveu virar traveco, é isso meu irmão?"

Valquíria - olha, essa coisa de traveco é uma coisa preconceituosa, é antiquada, olha só, isso aqui chama-se crossdresser! aí conquistando as coisas, né. Botaram as calças compridas, terninho, empregos e estão indo cada vez mais longe, o que tem demais um homem entrar no mundo das mulheres, botar uma saia, uma peruca, pintar a unha, num é?

Janete elogia a produção e a cor do esmalte. Fecha com "Ai, você está linda!"

Valquíria - Janete eu sabia que você ia me dar força, sabia? E eu estou me sentindo outro homem, sabe. Eu estou me sentindo livre, poderosa, eu vou dar uma guinada na minha vida, eu estou muito bem.
}

\section{Considerações finais}

\footnotetext{
${ }^{10}$ A cena "Breno avisa que se chama Valquíria" está disponível em: $<$ https://goo.gl/urj1uj>. Acesso em: $05 / 11 / 2016$.
}

INTERIN, v. 23, n. 2, jul./dez. 2018. ISSN: 1980-5276. 
Para este artigo, tais categorias e identidades representadas revelam uma ruptura na regulação binária da sexualidade, transgredindo as "hegemonias heterossexuais, reprodutivas e médico-jurídicas"11 (BUTLER, 2006, p. 19). Como Wittig afirma (apud BUTLER) "lésbica é o único conceito que eu conheço que está além das categorias de sexo" 12 (BUTLER, 2006, p. 19). Pode-se afirmar que todas as identidades supracitadas buscam ir além da categoria do sexo. Elas estão constantemente se reinventando, transitando entre o masculino e o feminino, o homossexual e o heterossexual, reproduzindo performances estereotipadas de gênero, mas ao mesmo desafiando-as.

A já clássica noção de gênero como performance de Judith Butler caberia aqui ao pensarmos que o gênero já não é mais parte da essência humana e sim parte de atributos performáticos e de construção. Para Alexandre do Vale, por exemplo, a desconstrução das noções de gênero e sexo não é só teórica, mas também performática. Quando Butler fala sobre drag, a autora afirma que "subverte inteiramente a distinção entre o espaço psíquico interior e exterior e efetivamente zomba tanto do modelo expressivo de gênero como da noção de uma verdadeira identidade de gênero"13 (BUTLER, 2006, p. 137). Se removermos a noção de paródia expressada mais adiante no capítulo da obra da autora, e pensarmos em desafio e não em piada (mockery), tais noções de subversão à norma binária podem ser exploradas a partir das identidades definidas acima. Como Butler afirma: "se a 'realidade' do gênero é constituída pela performance em si mesma, então não há como recorrer a um 'sexo' ou 'gênero' essencial e não realizado que as manifestações de gênero geralmente expressam. $O$ gênero é tão plenamente real quanto qualquer pessoa cujo desempenho esteja em conformidade com as expectativas sociais"14 (BUTLER, 2006, p. 203). Tais expressões vão além da ruptura do masculino e do feminino, quebram padrões de

\footnotetext{
11 Tradução livre do original: "heterosexual, reproductive, and medicojuridical hegemonies".

12 Tradução livre do original: "lesbian is the only concept I know of which is beyond the categories of sex".

13 Tradução livre do original: "fully subverts the distinction between inner and outer psychic space and effectively mocks both the expressive model of gender and the notion of a true gender identity".

${ }^{14}$ Tradução livre do original: "if the 'reality' of gender is constituted by the performance itself, then there is no recourse to an essential and unrealized 'sex' or 'gender' which gender performances generally express. Gender is as fully real as anyone whose performance complies with social expectations".
}

INTERIN, v. 23, n. 2, jul./dez. 2018. ISSN: 1980-5276. 
passivo/ativo, homem/ mulher, heterossexual/ homossexual e dominante/ dominado, por exemplo.

Portanto, é a partir de tais termos e da ideia de ruptura da normatividade que julgamos adequado discutir o espectro de masculinidades presente hoje na telenovela brasileira.

\section{REFERÊNCIAS}

ASSOCIAÇÃO BRASILEIRA DE LÉSBICAS, GAYS, BISSEXUAIS, TRAVESTIS E TRANSEXUAIS (ABLGBT). Manual de Comunicação LGBT: lésbicas, gays, bissexuais, travestis e transexuais. 2009. Disponível em: $<$ https://goo.gl/bVR6zg > . Acesso em: 05/11/2016.

BAKHTIN, Mikhail. Estética da criação verbal. Tradução de: Paulo Bezerra. São Paulo: Martins Fontes, 2003.

BERSANI, Leo. Is the rectum a grave and other essays. Chicago: The University of Chicago Press, 2010.

BOURDIEU, Pierre. A dominação masculina. Rio de Janeiro: Bertrand Brasil, 2007.

BUTLER, Judith. Gender trouble. New York: Routledge, 2006.

GIDDENS, Anthony. As transformações da intimidade. São Paulo: Editora da UNESP, 1993.

GOLDENBERG, Mirian. A crise da masculinidade na mídia. In: TRAVANCAS, Isabel; FARIAS, Patrícia. Antropologia e comunicação. Rio de Janeiro: Garamond, 2003, p. 169-179.

HALPERIN, David. How to be gay. Cambridge, London: The Belknap Press, 2012.

JAKUBASZKO, Daniela. A construção dos sentidos da masculinidade na telenovela A Favorita: um diálogo entre as representações da masculinidade na telenovela e as representações das manifestações discursivas do ambiente social brasileiro. 2010. Tese (Doutorado em Ciências da Comunicação) - Escola de Comunicações e Artes da Universidade de São Paulo, São Paulo, 2010. Disponível em: <https://goo.gl/UnriFp>. Acesso em: 05/11/2016.

JAKUBASZKO, Daniela. A representação das masculinidades na telenovela: entre o machismo, o modelo ideal e a ruptura com o modelo hegemônico da masculinidade. In: ALAIC, 12., 2014, Lima, Peru. Anais do XII Congreso Latinoamericano de 
Investigadores de la Comunicación. Lima, Peru: ALAIC, 2014. Disponível em: $<$ https://goo.gl/PtSrb8>. Acesso em 27.10.2016.

LAURETIS, Tereza (Org.). Queer theory: lesbian and gay sexualities. Bloomington: Indiana University Press, 1991.

LOPES, Maria Immacolata Vassallo de; Gómez, Guillermo Ororzco (Orgs.). Transnacionalização da ficção televisiva nos países Ibero-Americanos: Anuário Obitel, 2012. Porto Alegre: Sulina- Globo Universidade.

LOPES, Maria Immacolata Vassallo de; Gómez, Guillermo Orozco (Orgs.).

Relações de gênero na ficção televisiva: Anuário Obitel, 2015. Porto Alegre: Sulina - Globo Universidade.

LUGARINHO, Mario Cesar. Al Berto, In Memoriam. The Luso Queer Principle. In: Arenas, Fernando; Quinlan Susan Canty (editores). Lusosex. Gender and Sexuality in the Portuguese Speaking World. Minneapolis: University of Minnesota Press, 2002.

\section{MÉRIDA JIMENEZ, Rafael. Sexualidades transgressoras: Una antologia de} estúdios queer. Barcelona: Icaria Editorial, 2002.

MOTTER, Maria Lourdes; Jakubaszko, Daniela. Telenovela e realidade social: algumas possibilidades dialógicas. Comunicação \& Educação, Ano XII, Número 1, jan/abr 2007.

Recebido em: 28.06 .2017

Aceito em: 10.09.2017 